\title{
Chemically Precipitated Struvite Dissolution Dynamics over Time in Various Soil Textures
}

\author{
Ryder Anderson ${ }^{1}$, Kristofor R. Brye ${ }^{1^{*}}$ (1) , Lauren Greenlee ${ }^{2}$, Edward Gbur ${ }^{3}$ \\ ${ }^{1}$ Department of Crop, Soil, and Environmental Sciences, University of Arkansas, Fayetteville, USA \\ ${ }^{2}$ Department of Chemical Engineering, University of Arkansas, Fayetteville, USA \\ ${ }^{3}$ Agricultural Statistics Laboratory, University of Arkansas, Fayetteville, USA \\ Email: *kbrye@uark.edu
}

How to cite this paper: Anderson, R. Brye, K.R., Greenlee, L. and Gbur, E. (2020) Chemically Precipitated Struvite Dissolution Dynamics over Time in Various Soil Textures. Agricultural Sciences, 11, 567-591. https://doi.org/10.4236/as.2020.116036

Received: May 20, 2020

Accepted: June 19, 2020

Published: June 22, 2020

Copyright (c) 2020 by author(s) and Scientific Research Publishing Inc. This work is licensed under the Creative Commons Attribution International License (CC BY 4.0).

http://creativecommons.org/licenses/by/4.0/

\section{(cc) (i) Open Access}

\begin{abstract}
Phosphorus (P) is a fundamental nutrient in agricultural production and is one of three major components in common fertilizers. The majority of fertilizer-P sources are derived from phosphorus rock (PR), which has finite abundance; thus a sustainable source of $\mathrm{P}$ is imperative for future agricultural productivity. A potential sustainable $\mathrm{P}$ source may be the recovery of the mineral struvite $\left(\mathrm{MgNH}_{4} \mathrm{PO}_{4} \cdot 6 \mathrm{H}_{2} \mathrm{O}\right)$ from wastewater treatment plant effluent, but struvite behavior in soils of varying texture is not well characterized. The objective of this study was to assess the dissolution dynamics of a commercially available, wastewater-recovered struvite product over time in a plant-less, moist-soil incubation experiment with multiple soil textures. Chemically precipitated struvite (Crystal Green; CG) from municipal wastewater in pelletized and finely ground forms were added to soil cups at a rate of 24.5 $\mathrm{kg} \cdot \mathrm{P} \cdot \mathrm{ha}^{-1}$ containing soils of varying texture (i.e. loam, silty clay loam, and two different silt loams) from agricultural field sites in Arkansas. Soil cups were destructively sampled five times over a 6-month period to examine the change in water-soluble (WS) and weak-acid-extractable (WAE) P, K, Ca, $\mathrm{Mg}$, and $\mathrm{Fe}$ concentrations from their initial concentration. After 0.5 months, both WS-P and WAE-P concentrations increased $(P<0.05)$ more from initial concentrations of the finely ground CG in all soils, which averaged 76.2 and $158 \mathrm{mg} \cdot \mathrm{kg}^{-1}$, respectively, than in the pelletized CG treatment, which averaged 14.0 and $12.2 \mathrm{mg} \cdot \mathrm{kg}^{-1}$, respectively, across all soils. Over the course of the 6-month incubation, WS- and WAE-P concentrations generally increased over time in the pelletized and decreased over time in the finely ground treatment, confirming the slow-release property of pelletized CG that has been previously reported. The results of this study provide valuable insight regarding struvite-P behavior in various soils and provide further supporting evidence for the utilization of struvite as a potential alternative, sustainable
\end{abstract}


fertilizer-P source.

\section{Keywords}

Wastewater-Recovered Struvite, Soil Fertilizer Behavior, Extractable Soil Nutrients, Arkansas Soils

\section{Introduction}

Phosphorus $(\mathrm{P})$ is one of three primary macronutrients required by plants, and adequate concentrations are essential for optimal plant growth and health. Plants depend on $\mathrm{P}$ to perform many critical functions, such as root development, nucleic acid replication, as well as many energy transfer processes that utilize adenosine triphosphate (ATP). However, besides nitrogen $(\mathrm{N}), \mathrm{P}$ is the most limiting nutrient in agricultural production due to the complex behavior of $\mathrm{P}$ in the soil. Phosphorus undergoes several dynamic processes in the soil, such as clay adsorption, precipitation as secondary phosphate minerals, and immobilization by soil organic matter, all of which remove $\mathrm{P}$ from the soil solution and reduce $\mathrm{P}$ availability to plants [1] [2] [3]. Consequently, $\mathrm{P}$ fertilizers are often required to ensure that plants have adequate soil $\mathrm{P}$ throughout all growth stages.

Technological advances during the green revolution increased food production throughout the $20^{\text {th }}$ century and the demand for P fertilizers has proportionately increased [4]. However, rock phosphate (RP), the primary external source of $\mathrm{P}$, from which all synthetic fertilizer-P sources are derived, is limited in supply and could be depleted in as little as 100 years [5]. Since there is no alternative for $\mathrm{P}$ in agricultural production, a sustainable source of $\mathrm{P}$ will be an imperative resource to ensure that future food production is not compromised [4].

In the human $\mathrm{P}$ cycle, $\mathrm{P}$ cycling is inefficient and much of the $\mathrm{P}$ in the food production system ends up in soil and waste flows [6]. Approximately $98 \%$ of $\mathrm{P}$ in the human diet ultimately ends up in wastewater treatment plants (WWTPs) or septic systems. Normally in WWTPs, P is removed from wastewater effluent streams and is retained in the solid portion (i.e. sewage sludge; SS), which must be disposed of via incineration or transportation to landfills [7]. Sewage sludge disposal is often an expensive process in a WWTP's weekly operation. However, implementing $\mathrm{P}$ recovery technology has the potential to considerably reduce operation costs by reducing the volume of SS by up to 49\% [8] [9]. Consequently, P recovery from various waste streams using a variety of technologies has been an area of on-going research in recent decades and provides a potential solution to conventional fertilizer-P sources that are dependent on a finite RP supply.

One such wastewater-recovered $\mathrm{P}$ material is the mineral struvite $\left(\mathrm{MgNH}_{4} \mathrm{PO}_{4} \cdot 6 \mathrm{H}_{2} \mathrm{O}\right)$. Struvite has gained attention as a potentially sustainable, alternative fertilizer-P source due to the ability to recover both $\mathrm{N}$ and $\mathrm{P}$ from 
solid and liquid wastes into a single mineral. Struvite is a white, crystalline material consisting of equal molar concentrations of magnesium, ammonium, and phosphate and has been shown to have slow-release fertilizer properties [10] [11] [12].

Although struvite's agronomic effectiveness has been evaluated in a few plant studies [13] [14] [15] [16], the behavior of struvite in the soil environment has not been well studied. Specifically, even fewer studies have examined the behavior of the commercially available, wastewater-recovered, chemically precipitated struvite material Crystal Green (CG) in agronomic soils across various textures. The objective of this study was to assess the dissolution dynamics of finely ground and pelletized forms of CG in a plant-less, moist-soil incubation experiment with multiple soil textures (i.e. loam, silt loam, and silty clay loam). It was hypothesized that the smaller particle size of the finely ground material will have increasing WS- and WAE-P concentrations over time due to greater reactivity compared to the original, raw pellet form. It was also hypothesized that the WS-P concentrations will increase more in the loam and silty clay loam soils over time due to the greater WS-P concentrations of the initial soils compared to either silt loam soil.

\section{Materials and Methods}

\subsection{Soil Collection and Characterization}

Soils were collected from various row-crop agricultural settings throughout Arkansas to encapsulate a comprehensive range of physical and chemical soil properties. In December 2017, approximately 10, 20-L buckets of four soils were collected from the top 10 to $15 \mathrm{~cm}$. A Roxana loam (L; coarse-silty, mixed, superactive, nonacid, thermic Typic Udifluvent; $35^{\circ} 22^{\prime} 50.13^{\prime \prime} \mathrm{N} ; 94^{\circ} 14^{\prime} 1.84^{\prime \prime} \mathrm{W}$ ) and a

Dardanelle silty clay loam ( $\mathrm{SiCL}$; fine-silty, mixed, superactive, thermic Typic Argiudoll; $35^{\circ} 22^{\prime} 33.45^{\prime \prime N}$; $94^{\circ} 13^{\prime} 42.53^{\prime \prime} \mathrm{W}$ ) [17] were collected from the University of Arkansas Division of Agriculture's Vegetable Research Station in Kibler, AR. The Roxana soil had a recent history of vegetable production, while the Dardanelle soil had a recent history of soybean (Glycine max L.) production. A Calloway silt loam (SiL 1; fine-silty, mixed, active, thermic Aquic Fraglossudalf) [17], which was cropped to a wheat (Triticum aestivum)-soybean rotation for the previous 15 years, was collected from the Cotton Branch Experiment Station

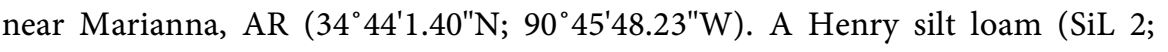
coarse-silty, mixed, active, thermic Typic Fragiaqualf) [17], which was cropped to a rice (Oryza sativa)-soybean rotation for at least the previous 5 years, was collected from the Pine Tree Research Station near Colt, AR $\left(35^{\circ} 746.74 " \mathrm{~N}\right.$; $\left.90^{\circ} 58^{\prime} 28.01^{\prime \prime} \mathrm{W}\right)$. The aquic soil moisture regime and history of rice cultivation has exposed the SiL 2 soil to extensive reducing soil conditions, whereas the SiL 1 soil has mostly experienced a history of oxidizing soil conditions. The climate throughout the regions from where the four soils used in this study were col- 
lected is humid temperate. After collection, soils were manually moist-sieved through a 7-mm mesh screen, air-dried for approximately two weeks, and stored in 20 -L buckets.

Three replicates of soil sub-samples were prepared for each soil for physical and chemical analyses. Sub-samples were oven-dried at $70^{\circ} \mathrm{C}$ for 48 hours, mechanically crushed, and sieved through a $2-\mathrm{mm}$ mesh screen. Particle-size analyses were conducted in triplicate for each soil using a modified 12-hr hydrometer method [18]. Weight-loss-on-ignition was used to determine soil organic matter (SOM) concentration, which was determined over a 2-hr period of combustion using a muffle furnace set at $360^{\circ} \mathrm{C}$ [19]. Soil pH and electrical conductivity (EC) were measured potentiometrically in a 1:2 (mass/volume) soil-towater paste ratio [20] [21]. Total carbon (TC) and total nitrogen (TN) concentrations were determined by high-temperature combustion using a VarioMax $\mathrm{CN}$ analyzer (Elementar Americas, Inc., Mt. Laurel, NJ) [22].

For each soil, an undisturbed bulk density was estimated using multiple regression relationships as detailed by Saxton et al. [23] using measured clay, sand, and SOM concentrations in the soil water characteristics sub-routine of the Soil-Plant-Atmosphere-Water Field \& Pond Hydrology (SPAW) model (version 6.02.75) [24]. Soil sub-samples were also collected from each air-dried soil, weighed, oven dried at $70^{\circ} \mathrm{C}$ for 48 hours, and reweighed to determine initial gravimetric water contents.

Extractable soil nutrient concentrations were also determined in triplicate for each of the soils. A water extraction was performed with a 1:10 soil mass:water volume ratio, where the soil suspensions were agitated for 1 hour, filtered through a $0.45-\mu \mathrm{m}$ filter, and analyzed by inductively coupled, argon-plasma spectrometry (ICAPS; Spectro Arcos ICP, Spectro Analytical Instruments, Inc., Kleve, Germany) [25] to determine water-soluble (WS) elemental [i.e. P, K, Ca, Mg, and Fe] concentrations. A Mehlich-3 extraction [26] was conducted with a 1:10 (mass:volume) soil:extractant solution ratio to determine weak-acid extractable (WAE) nutrient (i.e. $\mathrm{P}, \mathrm{K}, \mathrm{Ca}, \mathrm{Mg}$, and $\mathrm{Fe}$ ) concentrations. A strong-acid digest was conducted using the Environmental Protection Agency (EPA) method 3050B [27] and analyzed by ICAPS to determine total-recoverable (TR) elemental (i.e. $\mathrm{P}, \mathrm{K}, \mathrm{Ca}, \mathrm{Mg}$, and $\mathrm{Fe}$ ) concentrations.

\subsection{Fertilizer Analyses}

The commercially available, chemically precipitated struvite source, Crystal Green (Ostara Nutrient Recovery Technologies, Inc.) was evaluated in finely ground and pelletized forms to assess the effect of particle size on struvite behavior in soil. A sub-sample of pelletized CG material was mechanically ground to a powder in a small, commercially available coffee grinder. Chemical analyses (i.e. $\mathrm{pH}, \mathrm{EC}$, organic matter, TC, TN, and WS, WAE, and TR elements) were conducted on five replicate sub-samples for finely ground and pelletized CG using the same procedures as described above for soil samples. Water-soluble con- 
centrations represented environmentally relevant concentrations after interaction with rainwater. Weak-acid-extractable concentrations represented plantavailable concentrations. Total-recoverable concentrations represented concentrations that could potentially become environmentally available. Table 1 summarizes the chemical composition of the finely ground and pelletized CG material.

\subsection{Soil Incubation Experiment}

The soil incubation experiment was conducted over a six-month period from

Table 1. Summary of chemical properties [i.e. $\mathrm{pH}$, electrical conductivity (EC), organic matter (OM), total carbon (TC), total nitrogen (TN), and water-soluble, weak-acid-extractable, and total-recoverable $\mathrm{P}, \mathrm{K}, \mathrm{Ca}, \mathrm{Mg}$, and Fe concentrations] for finely ground and pelletized chemically precipitated struvite (Crystal Green, CG).

\begin{tabular}{|c|c|c|c|c|}
\hline \multirow{3}{*}{ Fertilizer Property } & \multicolumn{4}{|c|}{ Fertilizer-P Source } \\
\hline & \multicolumn{2}{|c|}{ Pelletized CG } & \multicolumn{2}{|c|}{ Powderized CG } \\
\hline & Mean & Standard Error & Mean & Standard Error \\
\hline $\mathrm{pH}$ & 8.78 & 0.13 & 8.50 & $<0.01$ \\
\hline $\mathrm{EC}\left(\mathrm{dS} \cdot \mathrm{m}^{-1}\right)$ & 226 & 2.2 & 298 & 4.1 \\
\hline $\mathrm{OM}\left(\mathrm{g} \cdot \mathrm{g}^{-1}\right)$ & 0.26 & 0.01 & 0.25 & 0.02 \\
\hline $\mathrm{TC}\left(\mathrm{g} \cdot \mathrm{g}^{-1}\right)$ & $<0.01$ & $<0.01$ & $<0.01$ & $<0.01$ \\
\hline $\mathrm{TN}\left(\mathrm{g} \cdot \mathrm{g}^{-1}\right)$ & 0.06 & $<0.01$ & 0.05 & $<0.01$ \\
\hline \multicolumn{5}{|c|}{ Water-soluble $\left(\mathrm{mg} \cdot \mathrm{kg}^{-1}\right)$} \\
\hline $\mathrm{P}$ & 216 & 1.6 & 281 & 2.2 \\
\hline $\mathrm{K}$ & 1.5 & 0.2 & 11.4 & 0.6 \\
\hline $\mathrm{Ca}$ & 11.6 & 0.8 & 8.9 & 0.5 \\
\hline $\mathrm{Mg}$ & 157 & 1.8 & 182 & 1.3 \\
\hline $\mathrm{Fe}$ & 1.2 & $<0.1$ & 0.5 & $<0.1$ \\
\hline \multicolumn{5}{|c|}{ Weak-acid-extractable $\left(\mathrm{mg} \cdot \mathrm{kg}^{-1}\right)$} \\
\hline $\mathrm{P}$ & 24,479 & 296 & 27,669 & 370 \\
\hline $\mathrm{K}$ & 230 & 1.3 & 253 & 13.1 \\
\hline $\mathrm{Ca}$ & 83 & 2.8 & 110 & 0.8 \\
\hline $\mathrm{Mg}$ & 21,444 & 254 & 24,025 & 337 \\
\hline $\mathrm{Fe}$ & 127 & 0.9 & 115 & 0.7 \\
\hline \multicolumn{5}{|c|}{ Total-recoverable $\left(\mathrm{mg} \cdot \mathrm{kg}^{-1}\right)$} \\
\hline $\mathrm{P}$ & 116,556 & 2480 & 113,186 & 2425 \\
\hline $\mathrm{K}$ & 842 & 4.4 & 853 & 2.7 \\
\hline $\mathrm{Ca}$ & 312 & 13.5 & 256 & 2.0 \\
\hline $\mathrm{Mg}$ & 83,234 & 1795 & 80,360 & 1962 \\
\hline $\mathrm{Fe}$ & 4505 & 45.8 & 4009 & 47.3 \\
\hline
\end{tabular}


June 3 to November 19, 2018. Plastic soil cups, $10.5 \mathrm{~cm}$ in diameter at the top and $4.5-\mathrm{cm}$ tall, were used for each soil-fertilizer replication. Five holes were drilled into the lids of the soil cups to allow some air exchange throughout the incubation.

All four soils (i.e. L, SiCL, SiL 1, and SiL 2) were used in the soil incubation. For each soil-fertilizer treatment combination, soil cups were prepared in triplicate and were destructively sampled five times over the 6-month incubation period (i.e. 0.5, 1, 2, 4, and 6 months). Approximately $150 \mathrm{~g}$ of air-dried soil were added to each plastic cup. Fertilizer treatments included pelletized CG (i.e. original material with no alteration), finely ground CG (i.e. powderized), and an unamended control. A fertilizer application of $170.7 \pm 5 \mathrm{mg}$ CG was applied to each soil cup, which was equivalent to a $56 \mathrm{~kg} \cdot \mathrm{P}_{2} \mathrm{O}_{5} \cdot \mathrm{ha}^{-1}\left(24.5 \mathrm{~kg} \cdot \mathrm{P} \cdot \mathrm{ha} \mathrm{a}^{-1}\right)$ fertilizer rate on a surface-area basis. The fertilizer rate was derived from the TR-P concentration of the CG material and a representative University of Arkansas' recommended P-fertilization rate for the calculated average soil test-P concentrations of the four soils. After fertilizers were manually applied to air-dried soil, soil cups were individually shaken in a vertical and a circular manner for approximately 10 seconds to simulate incorporation by tillage. Target bulk densities of the soil cups were estimated for each soil and ranged from $1.00 \mathrm{~g} \cdot \mathrm{cm}^{-3}$ in the $\mathrm{L}$ soil to $0.93 \mathrm{~g} \cdot \mathrm{cm}^{-3}$ in the SiCL. A total of 180 cups were prepared for the soil incubation experiment.

Soil cups were watered gravimetrically to a pre-determined target mass independently for each soil to mimic a wetting and drying cycle under natural field conditions. The target watering masses were derived from the estimated bulk densities and the measured gravimetric water contents of the air-dried soils. The target gravimetric water contents were determined from the SPAW model that estimated field moisture capacity for each soil and varied only slightly among soils $\left(0.23\right.$ to $\left.0.24 \mathrm{~g} \cdot \mathrm{g}^{-1}\right)$. Soil cups were initially watered one day after the fertilizers were added and incorporated. Soil cups were wetted to each soil's designated target weight using tap water from a low-flow-nozzle spray bottle. Every two weeks thereafter, all soil cups were rewetted to each soil's designated target weight using tap water. Over the 2-week period, the soil cups underwent a full wetting and drying cycle designed to imitate natural field conditions. An approximate soil bulk density was determined for each soil after several wetting and drying cycles based on the known mass of initial soil and total volume of a soil cup and measuring the height of soil in a cup after settle to obtain the new soil volume. After some initial settling, final soil bulk densities were approximately $1.08,1.09,1.09$, and $1.17 \mathrm{~g} \cdot \mathrm{cm}^{-3}$ for the SiCL, SiL $1, \operatorname{SiL} 2$, and L soils, respectively.

All soil cups were placed on a single, three-level, wooden shelf structure. The structure was $123 \mathrm{~cm}$ wide, $125.5 \mathrm{~cm}$ long, and $73 \mathrm{~cm}$ tall. Soil cups were randomly and evenly distributed among the three levels on the structure. Soil cups were rotated among the three shelves upon watering every two weeks to ensure 
the soil cups experienced uniform environmental conditions (i.e. air-flow exposure and light) throughout the 6-month incubation period.

Soil cups were destructively sampled after incubation periods of $0.5,1,2,4$, and 6 months. Soil was removed from the plastic cups, oven-dried for 48 hours at $70^{\circ} \mathrm{C}$, mechanically crushed, and sieved through a $2-\mathrm{mm}$ mesh screen. Water-soluble and WAE analyses were conducted, as previously described for initial soils, to evaluate extractable nutrient concentrations (i.e. $\mathrm{P}, \mathrm{K}, \mathrm{Ca}, \mathrm{Mg}$, and $\mathrm{Fe}$ ) over time. Soil $\mathrm{pH}$ and $\mathrm{EC}$ were also measured, as previously described, at each sampling interval.

The soil incubation experiment was completely conducted in a climate-controlled, laboratory setting. Air temperature and humidity fluctuations were measured throughout the duration of the soil incubation using an Acurite thermometer (model 00554SBDI, Chaney Instrument Co., Lake Geneva, WI) set on the three-tier shelf structure. Over the course of the 6-month incubation period, the ambient air temperature ranged from $21.1^{\circ} \mathrm{C}$ to $22.2^{\circ} \mathrm{C}$ and averaged $21.6^{\circ} \mathrm{C}$, while the ambient relative humidity ranged from $54 \%$ to $58 \%$ and averaged $56.5 \%$. Incubation cups received regular sunlight through a glass window in the laboratory where the incubation took place along with additional fluorescent lighting while lights were on during the day in the laboratory.

\subsection{Statistical Analyses}

Based on a completely randomized design, a one-factor analysis of variance (ANOVA) was conducted in SAS (version 9.4, SAS institute, Inc., Cary, NC) using the PROC GLIMMIX procedure to evaluate the effect of soil (i.e. L, SiCL, SiL 1, and SiL 2) on WS, WAE, and TR soil elemental (i.e. P, K, Ca, Mg, and Fe), SOM, TC, and TN concentrations, and $\mathrm{pH}$ and EC.

Based on a split-split-plot, randomized experimental design, a three-factor ANOVA was conducted in SAS using the PROC GLIMMIX procedure to evaluate the effects of soil (i.e. L, SiCL, SiL 1, and SiL 2), fertilizer treatment (i.e. pelletized CG, finely ground CG, and unamended control), time (i.e. 0.5, 1, 2, 4, and 6 months), and their interactions on the change in soil $\mathrm{pH}, \mathrm{EC}$, and WS and WAE elemental concentrations (i.e. $\mathrm{P}, \mathrm{K}, \mathrm{Ca}, \mathrm{Mg}$, and $\mathrm{Fe}$ ) from their initial magnitudes. The whole-plot factor was soil, the split-plot factor was fertilizer treatment, and the split-split-plot factor was time. When appropriate, treatment means were separated by least significant difference at the 0.05 level.

\section{Results and Discussion}

\subsection{Initial Soil Properties}

The four soils used in this experiment exhibited a wide range of physical and chemical properties. Initial sand, silt, clay, $\mathrm{pH}, \mathrm{EC}, \mathrm{SOM}, \mathrm{TC}, \mathrm{TN}$, and $\mathrm{C}: \mathrm{N}$ ratio differed among the soils used $(P<0.05$; Table 2$)$. Sand, silt, and clay concentrations varied greatly among soils due to the different soil textural classes represented 
Table 2. Summary of initial soil properties [i.e. sand, clay, and silt concentration, $\mathrm{pH}$, electrical conductivity (EC), soil organic matter (SOM), total carbon (TC), total nitrogen (TC), C:N ratio, water-soluble, weak-acid-extractable, and total-recoverable $\mathrm{P}, \mathrm{K}, \mathrm{Ca}, \mathrm{Mg}$, and Fe concentrations] among soils collected throughout Arkansas (i.e. L, SiCL, SiL 1, and SiL 2) used in the soil incubation.

\begin{tabular}{|c|c|c|c|c|}
\hline \multirow{2}{*}{ Soil Property } & \multicolumn{4}{|c|}{ Soil } \\
\hline & $\mathrm{L}$ & $\mathrm{SiCL}$ & SiL 1 & SiL 2 \\
\hline Sand $\left(g \cdot g^{-1}\right)$ & $0.44 \mathrm{a}^{*}$ & $0.07 \mathrm{~d}$ & $0.12 b$ & $0.10 \mathrm{c}$ \\
\hline Clay $\left(\mathrm{g} \cdot \mathrm{g}^{-1}\right)$ & $0.09 \mathrm{~d}$ & $0.37 \mathrm{a}$ & $0.14 \mathrm{~b}$ & $0.11 \mathrm{c}$ \\
\hline Silt $\left(g \cdot g^{-1}\right)$ & $0.46 \mathrm{~d}$ & $0.56 \mathrm{c}$ & $0.75 b$ & $0.79 \mathrm{a}$ \\
\hline $\mathrm{pH}$ & $6.17 c$ & $6.50 \mathrm{~b}$ & $6.53 b$ & $6.70 \mathrm{a}$ \\
\hline $\mathrm{EC}\left(\mathrm{dS} \cdot \mathrm{m}^{-1}\right)$ & $0.107 \mathrm{c}$ & $0.273 a$ & $0.169 b$ & $0.164 \mathrm{~b}$ \\
\hline $\operatorname{SOM}\left(g \cdot g^{-1}\right)$ & $0.007 \mathrm{~d}$ & $0.025 \mathrm{a}$ & $0.024 \mathrm{~b}$ & $0.019 c$ \\
\hline $\mathrm{TC}\left(\mathrm{g} \cdot \mathrm{g}^{-1}\right)$ & $0.003 \mathrm{~d}$ & $0.012 \mathrm{a}$ & $0.011 b$ & $0.009 \mathrm{c}$ \\
\hline $\mathrm{TN}\left(\mathrm{g} \cdot \mathrm{g}^{-1}\right)$ & $0.0003 c$ & $0.0011 \mathrm{a}$ & $0.0011 \mathrm{a}$ & $0.0008 \mathrm{~b}$ \\
\hline $\mathrm{C}: \mathrm{N}$ ratio & $10.5 b$ & $11.4 \mathrm{a}$ & $9.68 \mathrm{c}$ & $11.0 \mathrm{ab}$ \\
\hline \multicolumn{5}{|c|}{ Water-soluble $\left(\mathrm{mg} \cdot \mathrm{kg}^{-1}\right)$} \\
\hline $\mathrm{P}$ & $11.9 \mathrm{a}$ & $9.60 \mathrm{~b}$ & $5.47 \mathrm{c}$ & $3.70 \mathrm{~d}$ \\
\hline $\mathrm{K}$ & $44.7 \mathrm{a}$ & $44.7 \mathrm{a}$ & $25.3 \mathrm{c}$ & $28.3 \mathrm{~b}$ \\
\hline $\mathrm{Ca}$ & $34.0 \mathrm{c}$ & $74.3 \mathrm{a}$ & $62.7 \mathrm{~b}$ & $62.0 \mathrm{~b}$ \\
\hline $\mathrm{Mg}$ & $21.7 \mathrm{~b}$ & $28.0 \mathrm{a}$ & $23.3 b$ & $17.7 \mathrm{c}$ \\
\hline $\mathrm{Fe}$ & $47.9 \mathrm{a}$ & $47.9 \mathrm{a}$ & $47.9 \mathrm{a}$ & $47.9 \mathrm{a}$ \\
\hline \multicolumn{5}{|c|}{ Weak-acid-extractable $\left(\mathrm{mg} \cdot \mathrm{kg}^{-1}\right)$} \\
\hline $\mathrm{P}$ & $93.3 \mathrm{~b}$ & $143 a$ & $33.7 \mathrm{c}$ & $19.7 d$ \\
\hline K & $145 \mathrm{~b}$ & $485 a$ & $143 \mathrm{~b}$ & $158 \mathrm{~b}$ \\
\hline $\mathrm{Ca}$ & $933 c$ & $4328 \mathrm{a}$ & $1842 \mathrm{~b}$ & $2156 \mathrm{~b}$ \\
\hline $\mathrm{Mg}$ & $194 c$ & $774 a$ & $444 \mathrm{~b}$ & $365 b$ \\
\hline $\mathrm{Fe}$ & $201 b$ & $175 \mathrm{~d}$ & $186 \mathrm{c}$ & $459 \mathrm{a}$ \\
\hline \multicolumn{5}{|c|}{ Total-recoverable $\left(\mathrm{mg} \cdot \mathrm{kg}^{-1}\right)$} \\
\hline $\mathrm{P}$ & $371 \mathrm{c}$ & $672 a$ & $568 \mathrm{~b}$ & $297 d$ \\
\hline K & $1730 \mathrm{~b}$ & $5828 \mathrm{a}$ & $1525 c$ & $892 d$ \\
\hline $\mathrm{Ca}$ & $1440 \mathrm{~d}$ & $4463 a$ & $1757 \mathrm{c}$ & $2006 b$ \\
\hline $\mathrm{Mg}$ & $2433 b$ & $8544 a$ & $2429 b$ & $1236 c$ \\
\hline $\mathrm{Fe}$ & $8340 \mathrm{~d}$ & $27880 \mathrm{a}$ & $18230 \mathrm{~b}$ & $14297 \mathrm{c}$ \\
\hline
\end{tabular}

${ }^{*}$ Means in a row with different letters are different at $P<0.05$.

among soils. Sand concentration was lowest in the SiCL $\left(0.07 \mathrm{~g} \cdot \mathrm{g}^{-1}\right)$ and greatest in the $\mathrm{L}\left(0.44 \mathrm{~g} \cdot \mathrm{g}^{-1}\right.$; Table 2$)$. In contrast, silt and clay concentrations were lowest $\left(0.46\right.$ and $0.10 \mathrm{~g} \cdot \mathrm{g}^{-1}$, respectively) in the $\mathrm{L}$, while silt was the greatest in the SiL $2\left(0.79 \mathrm{~g} \cdot \mathrm{g}^{-1}\right)$ and clay was greatest in the SiCL soil $\left(0.37 \mathrm{~g} \cdot \mathrm{g}^{-1}\right.$; Table 2$)$. 
All soils exhibited a slightly acidic pH range between 6 and 7, with the most acidic condition being in the $\mathrm{L}(\mathrm{pH}=6.17)$ and the most alkaline conditions in the SiL $2(\mathrm{pH}=6.70$; Table 2). Additionally, soil $\mathrm{pH}$ was similar between the SiL $1(\mathrm{pH}=6.53)$ and SiCL $(\mathrm{pH}=6.50)$ soils $($ Table 2$)$. Both EC and SOM were lowest $\left(0.11 \mathrm{dS} \cdot \mathrm{m}^{-1}\right.$ and $0.01 \mathrm{~g} \cdot \mathrm{g}^{-1}$, respectively) in the $\mathrm{L}$, whereas EC was more than double $\left(0.27 \mathrm{dS} \cdot \mathrm{m}^{-1}\right)$ and the SOM concentration was more than three

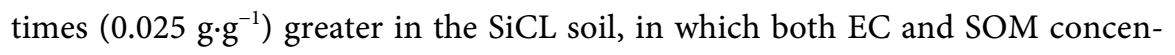
tration were the largest among the four soils (Table 2). Similar to EC and SOM, TC and TN were also lowest ( $3 \mathrm{~g} \cdot \mathrm{kg}^{-1} ; 0.3 \mathrm{~g} \cdot \mathrm{kg}^{-1}$, respectively) in the L soil and greatest (12 g. $\mathrm{kg}^{-1}$ and $1.1 \mathrm{~g} \cdot \mathrm{kg}^{-1}$, respectively) in the SiCL soil (Table 2). In addition, TN was also similar in both the SiL 1 and SiCL soils (Table 2). The initial C:N ratio was largest for the SiCL and SiL 2 soils, which averaged 11.2, while the SiL 1 soil had the lowest C:N ratio (9.68; Table 2).

As expected, WS concentrations were generally numerically lower than WAE concentrations, which, in turn, were substantially lower than TR concentrations. All WS nutrients (i.e. $\mathrm{P}, \mathrm{K}, \mathrm{Ca}$, and $\mathrm{Mg}$ ) differed among soils $(P<0.05)$, with the exception of WS-Fe, which did not differ among soils and averaged $47.9 \mathrm{mg} \cdot \mathrm{kg}^{-1}$ (Table 2). Water-soluble $\mathrm{P}$ was largest in the $\mathrm{L}\left(11.9 \mathrm{mg} \cdot \mathrm{kg}^{-1}\right)$ and lowest in the SiL 2 soil (3.70 mg. $\mathrm{kg}^{-1}$; Table 2). Water-soluble $\mathrm{K}$ was greatest in the $\mathrm{L}$ and SiCL soils (44.7 mg. $\mathrm{kg}^{-1}$ ) and lowest in the SiL 1 soil (25.3 $\mathrm{mg} \cdot \mathrm{kg}^{-1}$; Table 2$)$. The largest concentrations of WS-Ca $\left(74.3 \mathrm{mg} \cdot \mathrm{kg}^{-1}\right)$ and WS- $\mathrm{Mg}\left(28.0 \mathrm{mg} \cdot \mathrm{kg}^{-1}\right)$ were both in the SiCL soil, whereas the lowest WS-Ca concentration was in the L (34.0 $\left.\mathrm{mg} \cdot \mathrm{kg}^{-1}\right)$ and the lowest WS-Mg concentration was in the SiL 2 soil $\left(16.7 \mathrm{mg} \cdot \mathrm{kg}^{-1}\right.$; Table 2).

Similar to WS concentrations, all WAE concentrations (i.e. $\mathrm{P}, \mathrm{K}, \mathrm{Ca}, \mathrm{Mg}$, and Fe) differed among soils $(P<0.05$; Table 2$)$. Initial WAE-P $\left(143 \mathrm{mg} \cdot \mathrm{kg}^{-1}\right)$, -Ca $\left(4328 \mathrm{mg} \cdot \mathrm{kg}^{-1}\right),-\mathrm{Mg}\left(774 \mathrm{mg} \cdot \mathrm{kg}^{-1}\right)$, and $-\mathrm{K}\left(485 \mathrm{mg} \cdot \mathrm{kg}^{-1}\right)$ concentrations were all greatest in the SiCL soil, while WAE-P concentrations were lowest in the SiL 2 soil $\left(19.7 \mathrm{mg} \cdot \mathrm{kg}^{-1}\right)$, and both WAE-Ca and $-\mathrm{Mg}$ concentrations were lowest in the L soil (933 and $194 \mathrm{mg} \cdot \mathrm{kg}^{-1}$, respectively; Table 2). Additionally, WAE-K concentrations were similar and lowest among the L, SiL 1, and SiL 2 soils (145, 143, and $158 \mathrm{mg} \cdot \mathrm{kg}^{-1}$, respectively; Table 2). Of the WAE elements, only Fe was not significantly largest in the SiCL, but WAE-Fe was largest in the SiL 2 soil (459 $\mathrm{mg} \cdot \mathrm{kg}^{-1}$ ) and smallest in the SiCL soil (175 mg. $\mathrm{kg}^{-1}$; Table 2).

Total-recoverable elemental concentrations (i.e. $\mathrm{P}, \mathrm{K}, \mathrm{Ca}, \mathrm{Mg}$, and $\mathrm{Fe}$ ) all differed $(P<0.05)$ among soils (Table 2). Similar to WAE concentrations, the greatest TR-P (672 mg.kg-1), -K (5828 mg.kg-1 $)$, -Ca (4463 mg.kg-1), -Mg (8544 mg. $\left.\mathrm{kg}^{-1}\right)$, and $-\mathrm{Fe}\left(27,880 \mathrm{mg} \cdot \mathrm{kg}^{-1}\right)$ concentrations were in the SiCL soil (Table 2). The lowest TR-P $\left(297 \mathrm{mg} \cdot \mathrm{kg}^{-1}\right),-\mathrm{K}\left(892 \mathrm{mg} \cdot \mathrm{kg}^{-1}\right)$, and $-\mathrm{Mg}\left(1236 \mathrm{mg} \cdot \mathrm{kg}^{-1}\right)$ concentrations were in the SiL 2 soil, whereas the lowest TR-Ca $\left(1440 \mathrm{mg} \cdot \mathrm{kg}^{-1}\right)$ and $-\mathrm{Fe}$ (8340 $\mathrm{mg} \cdot \mathrm{kg}^{-1}$ ) concentrations were in the $\mathrm{L}$ soil (Table 2). Due to the variations in initial soil properties, particularly for the extractable elements, the measured responses for the unamended controls for each soil were subtracted from those 
measured for the amended treatments, such that results at each sample interval represented the change from the mean initial condition for each measured soil property.

\subsection{Change in Soil pH and Electrical Conductivity}

The change in $\mathrm{pH}$ and EC from the initial values was affected by one or more treatment factor evaluated (i.e. soil, fertilizer amendment, and/or sampling time) in the soil incubation. The change in soil $\mathrm{pH}$ from the initial, averaged across time, differed among fertilizer amendments within soils $(P<0.05$; Table 3$)$. An overall acidification effect was observed within the fertilized treatments (i.e. pellet and finely ground) among all soils (Figure 1). However, the decrease in soil $\mathrm{pH}$ from the initial was only different than a change of zero in the finely ground treatment $(-0.25 \mathrm{pH}$ units) in the $\mathrm{L}$ soil and the pellet $(-0.15 \mathrm{pH}$ units), finely ground $(-0.34 \mathrm{pH}$ units), and control $(-0.24 \mathrm{pH}$ units $)$ treatments in the SiL 1 soil (Figure 1). While the soil $\mathrm{pH}$ decreased from zero in the unamended control in the $\mathrm{SiL} 1$ soil, the change in $\mathrm{pH}$ in the unamended control treatment generally remained similar to zero (Figure 1). While a general acidifying effect was observed in both fertilized treatments, the pellet treatment did not exhibit a $\mathrm{pH}$ change as extensive as in the finely ground treatment and the $\mathrm{pH}$ change was similar to zero in three of the four soils (i.e. L, SiCL, and SiL 2). The less drastic $\mathrm{pH}$ change in the pelletized CG treatment was likely due to a slower dissolution rate of the CG material in pelletized form, thus less material interacted with the soil [11].

Averaged across fertilizer amendments, the change in soil $\mathrm{pH}$ also differed among soils over time $(P<0.05$; Table 3$)$. After 0.5 months, the change in soil $\mathrm{pH}$ was generally positive, with the exception of in the SiL 1 soil $(-0.04 \mathrm{pH}$ units), which did not change from the initial (Figure 2). However, the change in soil $\mathrm{pH}$ decreased among all soils over time thereafter, and by the 6-month sampling time, all soil pHs had decreased from the initial pH (Figure 2). The largest

Table 3. Analysis of variance summary of the effects of soil (S), fertilizer amendment (A), sample time (T), and their interactions on the change in soil-test $\mathrm{pH}$, electrical conductivity (EC), water-soluble (WS) and weak-acid-extractable (WAE) extractable nutrient $(\mathrm{P}, \mathrm{K}, \mathrm{Ca}, \mathrm{Mg}$, and $\mathrm{Fe})$ concentrations from initial soil values.

\begin{tabular}{|c|c|c|c|c|c|c|c|c|c|c|c|c|}
\hline \multirow{2}{*}{$\begin{array}{l}\text { Source of } \\
\text { Variation }\end{array}$} & $\Delta \mathrm{pH}$ & $\Delta \mathrm{EC}$ & $\Delta \mathrm{WS}-\mathrm{P}$ & $\Delta \mathrm{WS}-\mathrm{K}$ & $\Delta \mathrm{WS}-\mathrm{Ca}$ & $\Delta \mathrm{WS}-\mathrm{Mg}$ & $\Delta \mathrm{WS}-\mathrm{Fe}$ & $\Delta$ WAE-P & $\Delta \mathrm{WAE}-\mathrm{K}$ & $\Delta \mathrm{WAE}-\mathrm{Ca}$ & $\Delta$ WAE-Mg & $\Delta \mathrm{WAE}-\mathrm{Fe}$ \\
\hline & \multicolumn{12}{|c|}{$P$} \\
\hline A & $<0.01$ & $<0.01$ & $<0.01$ & $<0.01$ & $<0.01$ & $<0.01$ & $<0.01$ & $<0.01$ & 0.15 & 0.53 & $<0.01$ & $<0.01$ \\
\hline $\mathrm{T}$ & $<0.01$ & $<0.01$ & $<0.01$ & $<0.01$ & $<0.01$ & $<0.01$ & 0.26 & $<0.01$ & 0.04 & $<0.01$ & $<0.01$ & $<0.01$ \\
\hline $\mathrm{S} \times \mathrm{A}$ & $<0.01$ & $<0.01$ & $<0.01$ & $<0.01$ & $<0.01$ & $<0.01$ & $<0.01$ & $<0.01$ & 0.66 & 0.45 & $<0.01$ & $<0.01$ \\
\hline $\mathrm{S} \times \mathrm{T}$ & $<0.01$ & $<0.01$ & $<0.01$ & $<0.01$ & $<0.01$ & $<0.01$ & $<0.01$ & $<0.01$ & 0.05 & $<0.01$ & $<0.01$ & $<0.01$ \\
\hline $\mathrm{A} \times \mathrm{T}$ & $<0.01$ & $<0.01$ & $<0.01$ & $<0.01$ & $<0.01$ & $<0.01$ & $<0.01$ & $<0.01$ & 0.38 & 0.38 & $<0.01$ & $<0.01$ \\
\hline $\mathrm{S} \times \mathrm{A} \times \mathrm{T}$ & 0.62 & 0.02 & $<0.01$ & $<0.01$ & $<0.01$ & $<0.01$ & $<0.01$ & $<0.01$ & 0.72 & 0.10 & $<0.01$ & 0.34 \\
\hline
\end{tabular}



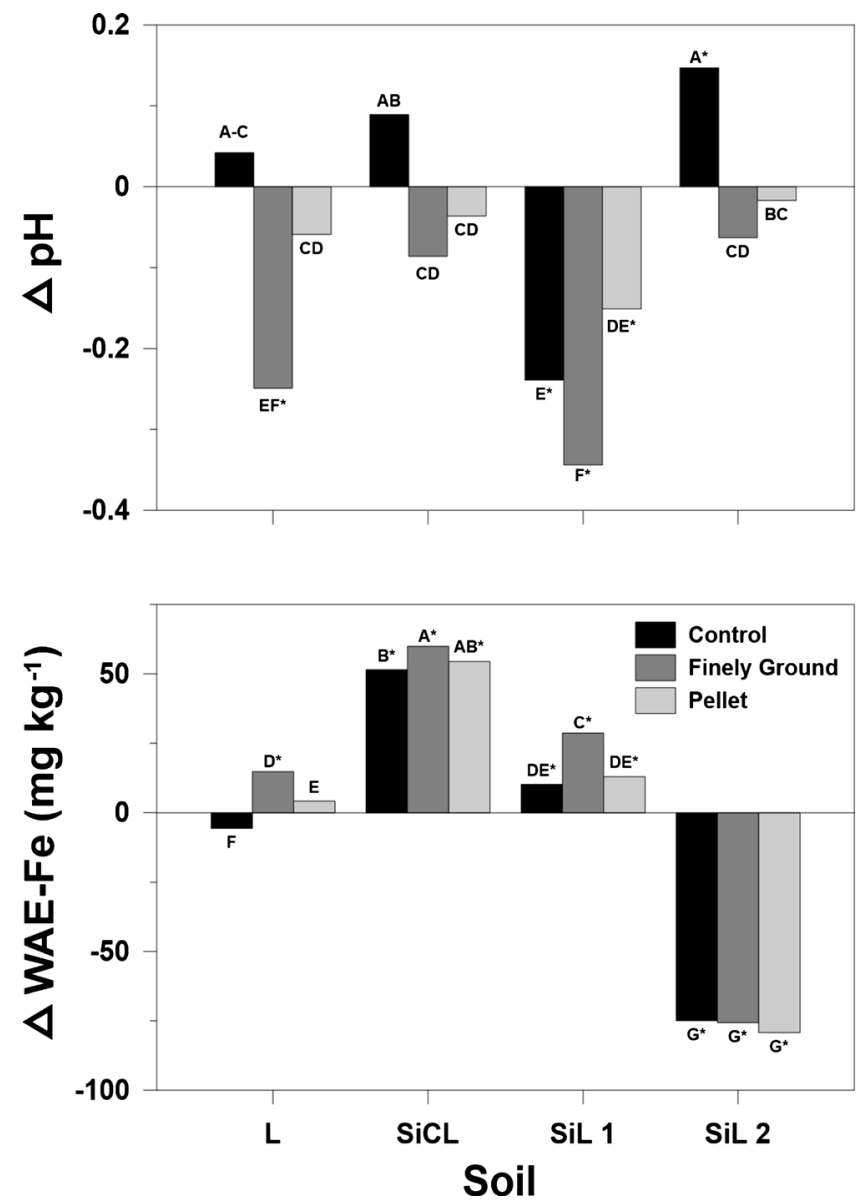

Figure 1. Fertilizer amendment effects, averaged over time, on the change in soil $\mathrm{pH}$ and weak-acid-extractable (WAE) soil Fe concentration from the initial among soils for the soil incubation. Means within a panel with different letters are different at $P<0.05$. An asterisk $\left.{ }^{*}\right)$ indicates mean value is different than zero at $P<0.05$.

decrease in $\mathrm{pH}$ occurred in the SiL 1 soil, which was $0.38 \mathrm{pH}$ units over the 6-month period. The decrease in soil $\mathrm{pH}$ among all soils was likely related to the acidification effect caused by the dissolution of the CG material over time, which likely occurred as a result of microbial nitrification of ammonia and was similar to the conclusion by Vaneeckhaute et al. [28]. In addition, the decrease in soil $\mathrm{pH}$ can also be caused by the displacement of $\mathrm{H}^{+}$from cation exchange sites by the addition of cations from the dissolving CG material, such as $\mathrm{Mg}^{2+}$ that has a greater affinity for exchange sites than does $\mathrm{H}^{+}$[12] [29].

The change in soil $\mathrm{pH}$, averaged among soils, also differed between fertilizer amendments over time $(P<0.05$; Table 3$)$. Within the first 0.5 months, the change in soil $\mathrm{pH}$ was generally positive among all fertilizer amendments, and increased from the initial in the control and pellet treatments $(0.15$ and $0.19 \mathrm{pH}$ units, respectively) and did not change from the initial in the finely ground treatment (Figure 3). Due to the alkalinity and low dissolution rate of struvite, the general $\mathrm{pH}$ increase from the initial in the first time interval was likely caused by both minimally dissolved struvite and soil being ground together for analysis, which 


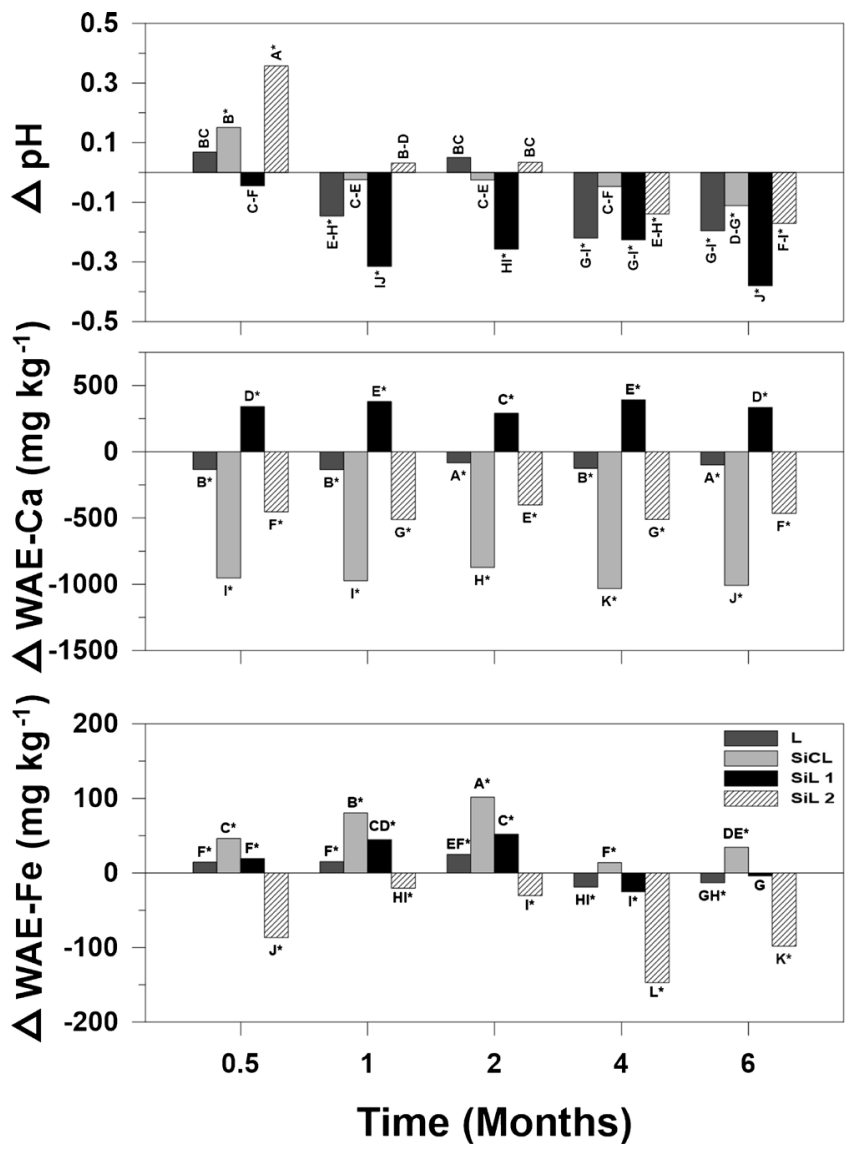

Figure 2. Soil effects, averaged over fertilizer amendments, on the change in soil $\mathrm{pH}$ and weak-acid-extractable (WAE) soil $\mathrm{Ca}$ and Fe concentrations from the initial over time for the soil incubation. Means within a panel with different letters are different at $P<0.05$. An asterisk $\left(^{*}\right)$ indicates mean value is different than zero at $P<0.05$.

resulted in a $\mathrm{pH}$ increase from the ground alkaline CG material itself [12] [30]. As the incubation advanced, soil $\mathrm{pH}$ decreased among fertilized amendments as the CG material continued to dissolve and react with the soil. After 1 month of incubation, and after 2, 4, and 6 months of incubation, the finely ground treatment had the largest decrease in $\mathrm{pH}$ compared to the pellet and unamended control treatments (Figure 3). After 6 months of incubation, soil $\mathrm{pH}$ decreased 0.33 and $0.24 \mathrm{pH}$ units from the initial in the finely ground and pelletized treatments, respectively. The decrease in soil $\mathrm{pH}$ from a change of zero occurred after only 1 month of incubation in the finely ground treatment, while the change in $\mathrm{pH}$ in the pelletized treatment took 4 months of incubation to differ than a change of zero, which was expected due to a slower dissolution rate of the pelletized CG (Figure 3).

The change in soil EC differed among fertilizer amendments within soils over time $(P<0.05$; Table 3$)$. The change in EC from the initial increased in each fertilizer amendment among all soils over time [31]. In the first 2 weeks, the change in soil EC in both pelletized and finely ground fertilizer treatments among all soils was greater than zero, with the exception of the pelletized and control 

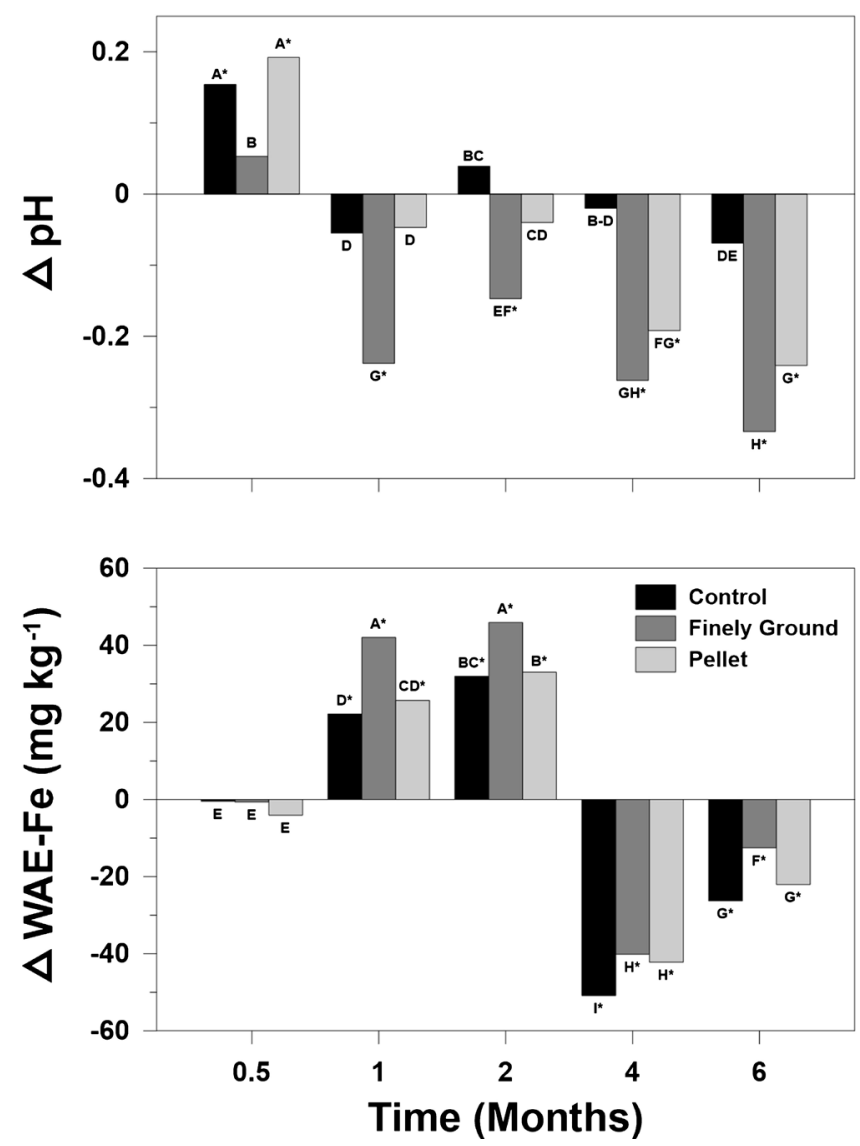

Figure 3. Fertilizer amendment effects, averaged over soils, on the change in soil $\mathrm{pH}$ and weak-acid-extractable (WAE) soil Fe concentration from the initial over time for the soil incubation. Means within a panel with different letters are different at $P<0.05$. An asterisk $\left(^{*}\right)$ indicates mean value is different than zero at $P<0.05$.

treatments in the SiCL soil, which was not greater than a change of zero until 2 months into the incubation [31]. Additionally, within the first 1 month of incubation, the change in soil EC in the finely ground fertilizer treatment was approximately double the change in soil EC in the pelletized treatment among each soil [31]. However, over time, the change in soil EC in both pelletized and finely ground fertilizer treatments was largest and similar among all soils by 6 months of incubation, except for the pelletized treatment in the SiCL, which was lower than finely ground treatment [31].

\subsection{Change in Water-Soluble Concentrations}

The change in all water-soluble soil concentrations (i.e. $\mathrm{P}, \mathrm{K}, \mathrm{Ca}, \mathrm{Mg}$, and $\mathrm{Fe}$ ) differed among soil-fertilizer-amendment combinations over time $(P<0.05$; Table 3). Among all measured concentrations, WS-P was impacted the most by fertilizer amendments over time. In all soils, the change in WS-P concentration was initially greatest with the finely ground CG (Figure 4), which was likely the result of increased soil-fertilizer contact of the finely ground material, which resulted in a more rapid dissolution of $\mathrm{P}$ and incorporation into the soil [11] [29]. 


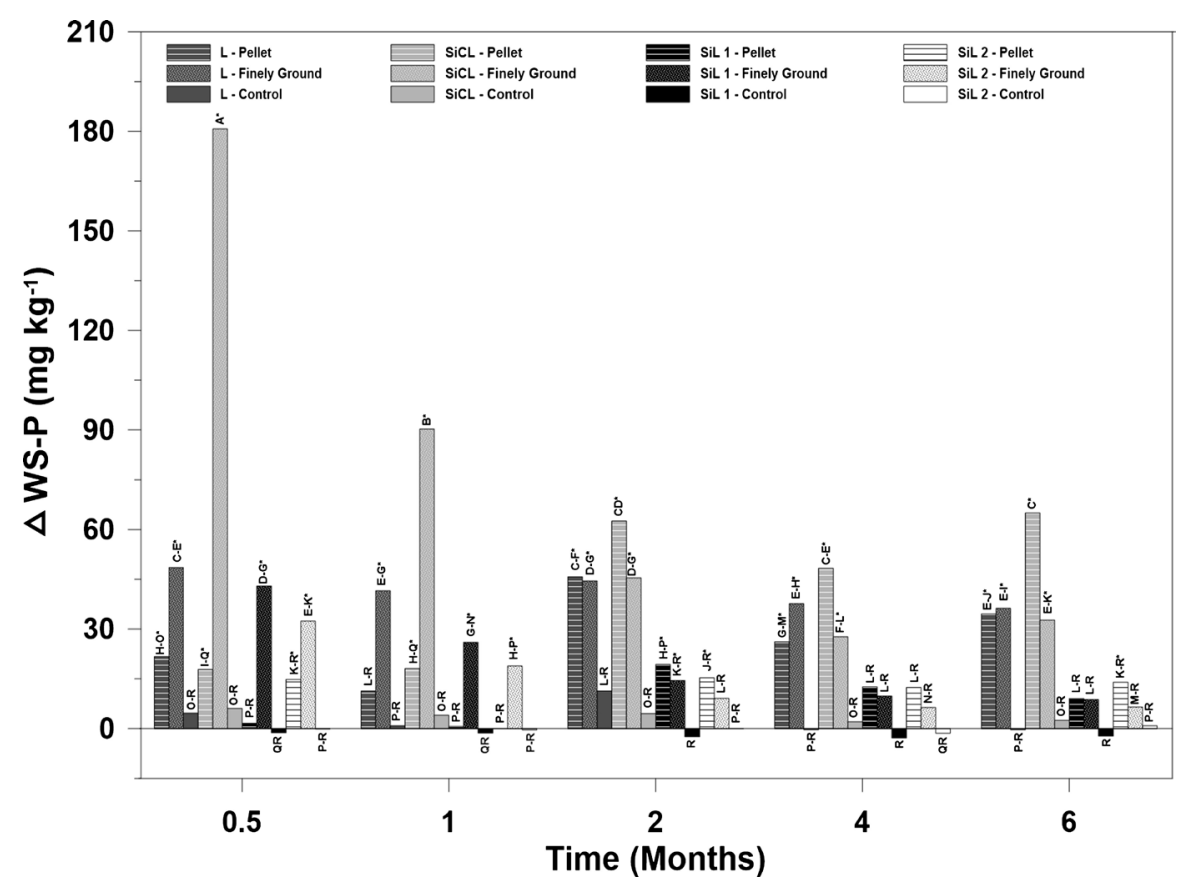

Figure 4. Fertilizer amendment-soil combination effects on the change in water-soluble $\mathrm{P}$ $(\Delta$ WS-P) concentration from the initial over time for the soil incubation. Means with different letters are different at $P<0.05$. An asterisk $\left.{ }^{*}\right)$ indicates mean value is different than zero at $P<0.05$.

Although the finely ground CG treatment had a significantly larger WS-P concentration than the pelletized CG treatment, the theoretical maximum P concentration (135 $\left.\mathrm{mg} \cdot \mathrm{kg}^{-1}\right)$ was exceeded and likely was caused by some incorporation of the fertilizer material upon destructive sampling. However, as time progressed, the change in WS-P concentrations from the finely ground CG generally decreased after the 0.5 -month sampling and was similar to the pelletized CG in all soils by the 6-month sampling, with the exception of in the SiCL soil in which the pelletized treatment was greater than the finely ground treatment (Figure 4). The diminishing dissolution of finely ground struvite over time was a trend that was also observed by Nongqwenga et al. [32] and was likely caused by fixation reactions (i.e. precipitation of $\mathrm{Fe}$ and $\mathrm{Al}$ phosphates, immobilization by soil microbes, and binding to clays) in the soil over time. A decreasing change in WS-P concentration was not prevalent in the pelletized CG because the gradual dissolution of the pelletized treatment had a reduced P-fixation effect on the soil as the pelletized CG slowly solubilized and released P over time [11]. The change in WS-P concentrations in the pelletized CG in the SiCL soil was greater at the 6- than at the 0.5-month sampling, which was expected, but did not occur in the other soils (Figure 4). The general trend in WS-P concentration in the pelletized amendment was a positive change from the initial, where WS-P concentration with the pelletized CG numerically increased from the initial in three of the four soils (i.e. L, SiCL, and SiL 2, respectively). However, the change in WS-P over time with the pelletized CG was complex and varied among soil textures through- 
out the incubation.

The change in WS- $\mathrm{K}$ concentrations also differed among soil-fertilizer combinations over time $(P<0.05$; Table 3$)$. No clear trend in the change WS-K emerged among fertilizer amendments in the SiCL soil [31]. However, in the L, SiL 1, and SiL 2 soils, a general increase in WS-K concentrations from the initial was observed in the finely ground and pelletized treatments over time [31]. The change in WS-K concentrations in the L, SiL 1, and SiL 2 soils was normally more dynamic in the pelletized treatments, whereas the finely ground treatments were generally more static over time [31]. Initially, the change in WS-K concentrations was generally negative in the pelletized and unamended control treatments and generally positive in the finely ground treatments among soils [31]. However, by the 6-month sampling, the change in WS-K concentration from the initial was greater than zero in all fertilized treatments in each soil, with the exception of the finely ground treatments in the L and SiCL soils, which did not differ from the initial [31].

Apart from the finely ground and unamended control treatments in the SiCL soil, the change in WS-Ca concentration generally increased among all other fertilizer treatments and soils over time [31]. In the L, SiL 1, and SiL 2 soils, the change in WS-Ca concentrations in all treatments increased after the 0.5-month sampling as the incubation progressed. By 6 months, the change in WS-Ca concentration was the largest in both the finely ground and pelletized treatments in the L, SiL 1, and SiL 2 soils, and the changes in both treatments were greater than zero among all soils [31]. Although the change in WS-Ca varied in the SiCL soil over time, the finely ground and pelletized treatments were also similar by the 6-month sampling [31]. Additionally, the change in WS-Ca in all finely ground treatments was greater than that in the unamended control treatments at every sampling, whereas the change in WS-Ca in all pelletized treatments was only greater than the change in the unamended control after the 2-month sampling [31].

Similar to the change WS-P, the change in WS-Mg concentration among fertilized amendments (i.e. pelletized and finely ground CG) was dependent on the dissolution rate of CG and followed a similar trend over time. The dissolution of CG in the finely ground and pelletized forms occurred at different rates, which led to a lower initial change in WS-Mg concentrations in the pelletized compared to the finely ground treatment in all soils (Figure 5). Over time, the change in WS-Mg was positive and increased in the pelletized treatment in all soils and was greatest by the 6-month sampling (Figure 5). The change in WS-Mg in the finely ground was $\sim 10$ times greater than that in the pelletized treatment in each soil at the 0.5 -month sampling, which was likely caused by the introduction of $\mathrm{Mg}$ ions in the soil from the relatively rapid dissolution of the finely ground CG material. After 1 month, the change in soil WS-Mg concentration in the finely ground treatment generally remained constant in all soils, with the exception of in the L, in which the change in WS-Mg concentration increased over 
time (Figure 5). By the 6-month sampling, the changes in WS-Mg concentration were similar between finely ground and pelletized treatments in the L and SiCL soils and greater in the finely ground than in the pelletized treatment in the SiL 1 and SiL 2 soils (Figure 5).

In contrast to the aforementioned WS elements (i.e. $\mathrm{P}, \mathrm{K}, \mathrm{Ca}$, and $\mathrm{Mg}$ ), the changes in WS-Fe concentration among soil-fertilizer combinations over time were complex and no clear relationship was present [31]. The changes in WS-Fe concentration from the initial soil condition in all treatments were all significantly negative [31]. The greatest magnitude in change of WS-Fe concentrations occurred in all fertilizer treatments in the SiL 2 soil, followed by all fertilizer treatments in the L soil, which decreased the most from the initial condition and differed from a change of zero [31]. While the change in WS-Fe was significant within fertilizer amendments among soils over time, time had only a minimal effect on the change in WS-Fe concentration [31].

\subsection{Change in Weak-Acid-Extractable Soil Concentrations}

Overall, many WAE soil concentrations generally followed similar trends as their WS concentrations. The change in WAE soil concentrations was also generally numerically larger than the change in WS concentrations likely due to the increased availability from the weak-acid extraction. Similar to WS concentrations, the change in WAE concentrations was also affected by one or more treatment factors (i.e. soil, fertilizer amendment, and time). The change in WAE-P differed among fertilizer amendments within soils over time $(P<0.05$; Table 3$)$.

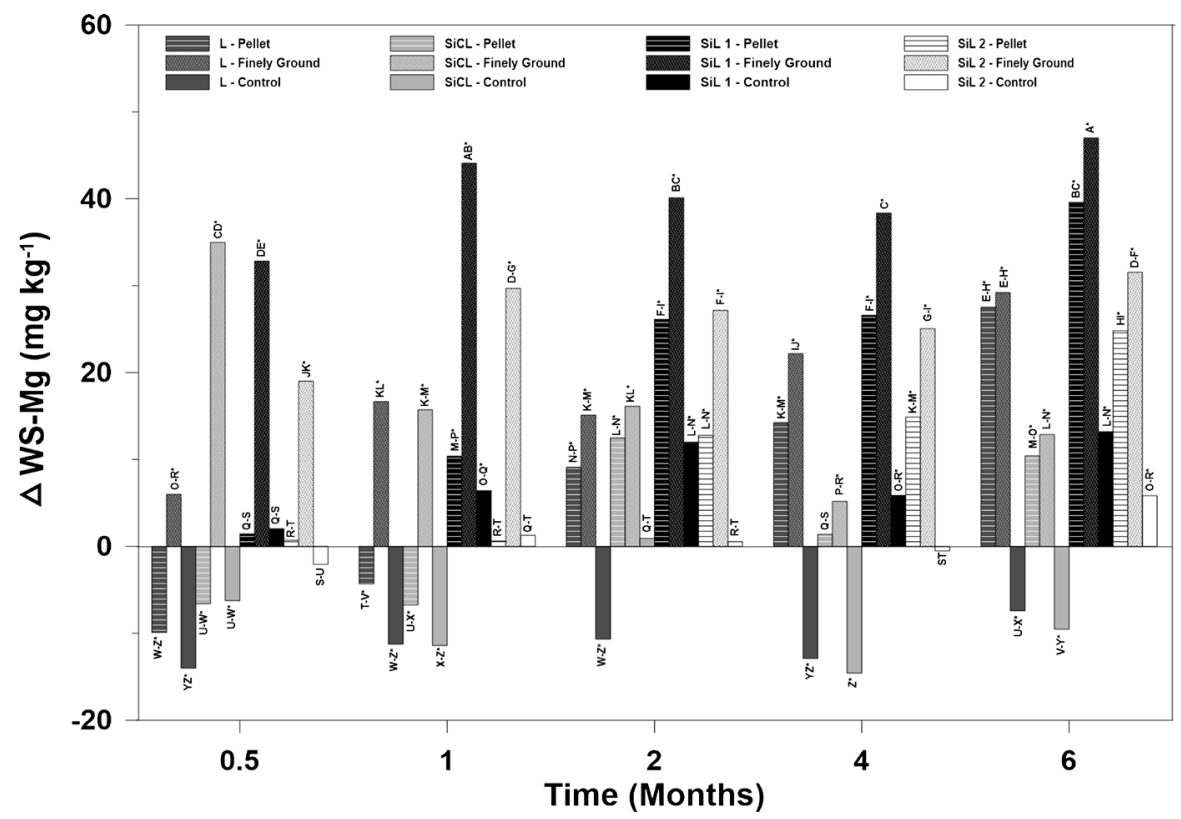

Figure 5. Fertilizer amendment-soil combination effects on the change in water-soluble $\mathrm{Mg}(\Delta \mathrm{WS}-\mathrm{Mg})$ concentration from the initial over time for the soil incubation. Means with different letters are different at $P<0.05$. An asterisk $\left.{ }^{*}\right)$ indicates mean value is different than zero at $P<0.05$. 
The transformation of both WS- and WAE-P from the initial soil concentration followed a similar trend. In both WS and WAE, the change in P concentration was initially greatest in the finely ground CG compared to the pelletized or unamended control treatments among all soils (Figure 6). The greatest initial change in WAE-P concentrations occurred in the finely ground treatment in the SiCL soil after the 0.5 -month sampling (274 mg. $\mathrm{kg}^{-1}$; Figure 6 ). The greater WAE-P concentrations in the finely ground CG in the SiCL were likely related to the greater initial WAE-P concentration in the SiCL soil, which allowed for a greater concentration of $\mathrm{P}$ to exist in soil solution. In addition, as previously mentioned, the greater surface area caused the finely ground material to become available in the soil incubation earlier than with the pelletized material. However, the greater initial clay content, OM, and Fe concentration in the SiCL soil greatly reduced the WAE-P concentration from the 0.5 -month sampling, as $\mathrm{P}$ transformed into less available forms, which was similar to previous reports [12] [32].

The change in WAE-P concentration in the pelletized treatment in all soils did not differ from a change of zero until the 2-month sampling, in which WAE-P concentrations increased in all pelletized treatments in all soils (Figure 6). Over time, the change in WAE-P concentration generally decreased in all finely ground and increased in all pelletized treatments (Figure 6). The relatively slow availability of WAE-P in the pelletized CG was indicative of the gradual dissolution of the CG pellets over time [11]. By 6 months, the change in WAE-P concentrations was similar between the finely ground and pelletized treatments in

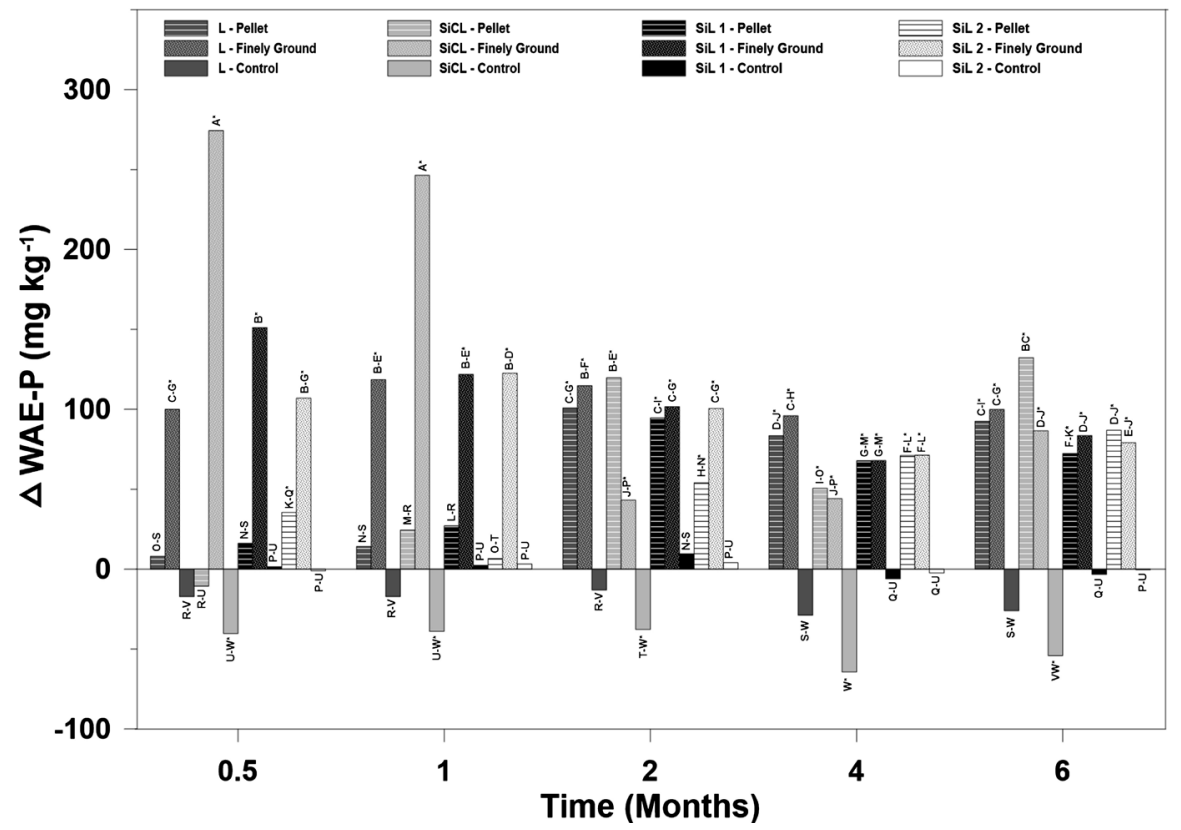

Figure 6. Fertilizer amendment-soil combination effects on the change in weak-acid-extractable soil $\mathrm{P}(\triangle \mathrm{WAE}-\mathrm{P})$ concentration from the initial over time for the soil incubation. Means with different letters are different at $P<0.05$. An asterisk $\left(^{*}\right)$ indicates mean value is different than zero at $P<0.05$. 
each individual soil, with the exception of the SiCL soil, in which the pelletized had a greater change in WAE-P $\left(+132 \mathrm{mg} \cdot \mathrm{kg}^{-1}\right)$ than the finely ground treatment $\left(+86.6 \mathrm{mg} \cdot \mathrm{kg}^{-1}\right.$; Figure 6). Nongqwenga et al. [32] suggested that struvite dissolution is limited in soils with large background $\mathrm{P}$ and/or $\mathrm{Mg}$ concentrations, yet this was not observed in this study, as the change in WAE-P concentrations were generally lower in all treatments in the SiL 1 and SiL 2 soils, which had low initial $\mathrm{P}$ and $\mathrm{Mg}$ concentrations, and generally greater in the $\mathrm{SiCL}$ and $\mathrm{L}$ soils (Figure 6). Additionally, multiple studies have suggested that soil $\mathrm{pH}$ is a primary factor controlling struvite-P release [11] [33] [34], yet this study showed no difference between WAE-P concentrations by the 6-month sampling in the $\mathrm{L}$ and SiL 2 soils with soil pHs of 6.17 and 6.70, respectively (Figure 6).

The change in WAE-K concentration differed among soils and differed over time $(P<0.05$; Table 3$)$. Averaged across fertilizer amendments and time, the change in WAE-K was negative and differed from a change of zero in all soils. The change in WAE-K concentration was the least negative and similar in the $\mathrm{L}$ $\left(-20.1 \mathrm{mg} \cdot \mathrm{kg}^{-1}\right)$ and SiL $1\left(-28.4 \mathrm{mg} \cdot \mathrm{kg}^{-1}\right)$ soils and had the greatest decrease from zero in the SiCL soil $\left(-128.7 \mathrm{mg} \cdot \mathrm{kg}^{-1}\right)$. While the effect of time was significant, averaged across fertilizer amendments and soils, an obvious trend was not observed. The change in WAE-K was again negative and differed from a change of zero at all sampling times, where the most-negative change from the initial condition in WAE-K concentration occurred by the 2-month sampling (-61.9 $\left.\mathrm{mg} \cdot \mathrm{kg}^{-1}\right)$ and the most-positive change occurred by the 6 -month sampling $\left(-42.8 \mathrm{mg} \cdot \mathrm{kg}^{-1}\right)$.

The change in WAE-Ca concentration differed among soils over time $(P<$ $0.05)$, but, similar to WAE-K, the change in WAE-Ca concentration was unaffected by fertilizer amendment (Table 3). While the change in WAE-Ca concentrations differed among soils over time, time generally did not have a substantial impact, with only slight variations in WAE-Ca in each soil over the duration of the incubation. In addition, two of the four soils (i.e. SiL 1 and SiL 2) had similar WAE-Ca concentrations at the 0.5 and 6 -month samplings (Figure 2). The change in WAE-Ca concentrations predominantly differed among soils, where the greatest change in WAE-Ca concentration occurred in the SiL 1 soil at every time interval (Figure 2). The change in WAE-Ca concentration in the SiL 1 soil was the only positive change that occurred, where all other soils experienced a negative change in WAE-Ca concentration from the initial condition (Figure 2). The largest decrease in WAE-Ca occurred in the SiCL soil in every sampling, which was approximately double and triple the decrease in the SiL 2 and L soils, respectively (Figure 2). Considerable variability was measured in initial WAE-Ca concentrations and likely had the largest impact on the change in WAE-Ca concentrations over time.

Like WS- and WAE-P, the change in WS- and WAE-Mg demonstrated similar trends. Similar to WS-Mg, the change in WAE-Mg concentration differed among soil-fertilizer treatment combinations over time $(P<0.05$; Table 3$)$. Among all 
measured concentrations, WAE-Mg concentrations were impacted the most by the different soils used in the incubation. The SiCL and SiL 2 soils generally had a negative change in WAE-Mg throughout the soil incubation, yet exhibited a similar trend in the change in WAE-Mg over time to the L and SiL 1 soils, which had a positive change in WAE-Mg over time (Figure 7). The change in WAE-Mg was generally initially greatest in the finely ground treatment in all soils at the 0.5-month sampling (Figure 7), which was again likely related to the influx of $\mathrm{Mg}$ ions from the finely ground CG material. However, after the 0.5 -month sampling, the change in WAE-Mg concentration differed among soils within the finely ground treatment.

The change in WAE-Mg in the SiL 1 and SiL 2 soils decreased after 1 month and remained fairly consistent thereafter. The change in WAE-Mg concentration in the SiCL soil decreased for two months and then remained fairly consistent thereafter. The change in WAE-Mg concentration in the $\mathrm{L}$ soil remained similar throughout the incubation (Figure 7). The differences in WAE-Mg concentrations among the four soils likely reflected the differences in initial soil properties among the soils, namely clay content, which subsequently affected the soils' cation exchange capacity and ability to retain cations like Mg.

The pelletized material had an opposite trend from the finely ground material, where the pelletized treatment initially had the smallest change in WAE-Mg concentration by the 0.5-month sampling in all soils (Figure 7). By the 2-month sampling, all pelletized treatments had an increased change in WAE-Mg concentration (Figure 7). The increased positive change in WAE-Mg concentration

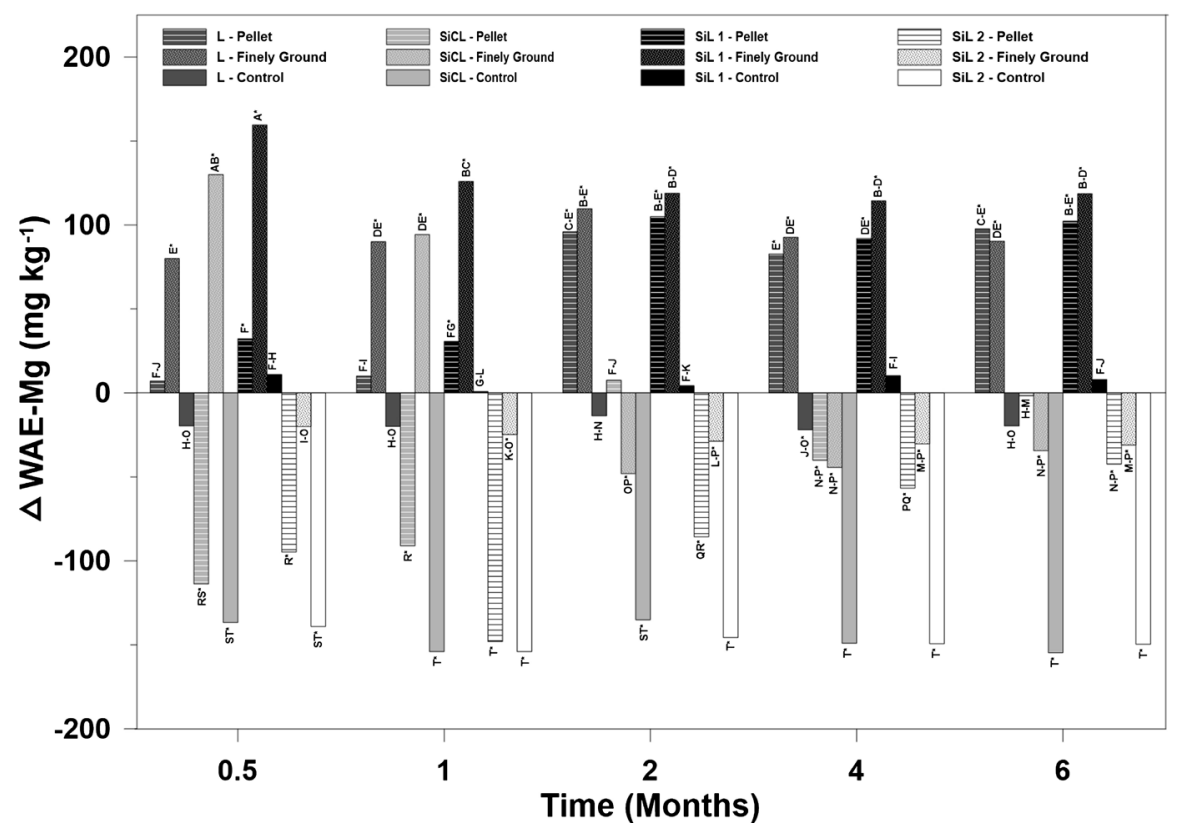

Figure 7. Fertilizer amendment-soil combination effects on the change in weak-acid-extractable soil $\mathrm{Mg}(\triangle \mathrm{WAE}-\mathrm{Mg})$ concentration from the initial over time for the soil incubation. Means with different letters are different at $P<0.05$. An asterisk $\left.{ }^{*}\right)$ indicates mean value is different than zero at $P<0.05$. 
in the pelletized treatment at the 2-month time interval was likely caused by the start of CG dissolution in the pelletized treatments. After 2 months, the change in WAE-Mg remained fairly consistent in all pelletized treatments and, by 6 months, the change in WAE-Mg concentrations in the pelletized treatment was similar to that in the finely ground treatment in three of the four soils (i.e. L, SiL 1 , and SiL 2), and was greater in the pelletized than in the finely ground treatment in the SiCL soil (Figure 7). Generally, both fertilized treatments had larger (i.e. positive) changes than the unamended control in each soil at every sampling time.

Averaged across sampling times, the change in WAE-Fe concentrations differed among fertilizer amendments within soils $(P<0.05$; Table 3$)$. In the $\mathrm{L}, \mathrm{SiCL}$, and SiL 1 soils, the finely ground treatment had the largest change in WAE-Fe concentrations compared to either the unamended control or pelletized treatment, with the exception of the pelletized treatment in the SiCL soil, which had a similar change in WAE-Fe as the finely ground treatment (Figure 1). Additionally, the change in WAE-Fe concentrations in both SiCL and SiL 1 soils were the only soils that exhibited a positive change in both finely ground and pelletized treatments that were also different than a change of zero (Figure 1). In the L soil, only the finely ground treatment had a change greater than zero, whereas the pelletized and control treatments had changes that were similar to zero (Figure 1). The change in WAE-Fe concentrations in the SiL 2 soil was significantly negative in all fertilizer treatments (Figure 1).

Averaged across fertilizer treatments, WAE-Fe concentrations also differed among soils over time $(P<0.05$; Table 3$)$. The change in WAE-Fe was the greatest in the SiCL soil and smallest in the SiL 2 soil at every sampling time (Figure 2). The change in WAE-Fe concentrations in all soils generally increased at each time interval to the 2-month sampling, where thereafter the change in WAE-Fe concentration decreased (Figure 2). By 6 months, the change in WAE-Fe concentrations was only positive and different than a change of zero in the SiCL soil (Figure 2).

Averaged across soils, the change in WAE-Fe concentration differed among fertilizer amendments over time $(P<0.05$; Table 3$)$. The change in WAE-Fe concentration was the greatest in the finely ground treatment and larger than in the unamended control at every time interval, whereas the pelletized treatment was similar to the unamended control at every time interval (Figure 3). Additionally, the change in WAE-Fe concentration generally increased from the initial condition after 1 and 2 months and decreased in all treatments thereafter (Figure 3). Between the 2- and 4-month samplings, the largest change in WAE-Fe concentrations occurred, with a decrease in all treatments of $\geq 70 \mathrm{mg} \cdot \mathrm{kg}^{-1}$ (Figure 3).

\subsection{Implications}

As a substance that was once viewed as a pipe-clogging, problematic WWTP 
by-product [9], struvite has recently gained attention as an attractive option in sustainable development due to the fertilizer potential of the recovered material. Controlled struvite recovery has the potential to recycle $\mathrm{P}$ from a number of different waste sources from various sectors, including the agricultural [10] [35], industrial [36], and municipal sectors [37] [38].

Phosphorus recovery in the form of struvite precipitation can preserve water quality nationwide and can potentially reduce future dependence on conventional, RP-derived P fertilizers [39] [40]. Struvite's effectiveness as a recovered fertilizer-P source has the potential to provide a sustainable source of $\mathrm{P}$ in the global agricultural production system, thus providing food security for future generations. In addition, struvite recovery in WWTPs can lead to a reduction in $P$ and N loads of the side-stream and SS in WWTPs [9] [41].

Though no plants were used in this incubation study, unless soil EC, $\mathrm{pH}$, and WS or WAE elemental concentrations changed to beyond optimum ranges or threshold levels for optimal growth for a particular crop, there would likely be little negative effects on crop productivity or soil quality. However, the greater reactivity of the finely ground compared to the original pelletized CG material in the loam soil resulted in a large enough $\mathrm{pH}$ decrease to drop the soil $\mathrm{pH}$ below 6.0 (Figure 1), which could negatively affect plant productivity and/or nutrient availability if not corrected with a liming material. While the CG materials caused similar magnitudes of $\mathrm{pH}$ decrease in the other three soils as well, the initial soil $\mathrm{pH}$ of the other three soils was larger, such that the resulting decrease in soil $\mathrm{pH}$, on average, was still not enough to lower soil $\mathrm{pH}$ below 6.0. Similarly, the changes in soil $\mathrm{Ca}$ and $\mathrm{Fe}$ among soils and over time, in which both $\mathrm{Ca}$ and $\mathrm{Fe}$ had relatively large initial concentrations in all soils (Table 2), would likely have little to no negative effects on crop productivity or soil quality. The general increase in WS and WAE P and WS Mg over time from both CG materials would be expected to enhance plant productivity in all soils. However, if the CG material was not incorporated into the soil and left on the soil surface, the potential for off-site transport of dissolved or sediment-bound P could negatively impact the surrounding aquatic environment if runoff $\mathrm{P}$ entered nearby waterways. Despite the mixed results for WAE Mg, increasing or decreasing over time depending on the specific soil, WAE Mg concentrations generally did not decrease enough to potentially cause a plant-Mg deficiency in any of the four soils.

\section{Conclusions}

While the agronomic applications of recovered struvite have been assessed in several small plant studies, the soil-fertilizer interactions between wastewater-recovered struvite and multiple soil textures have not been well studied, specifically in agronomic soils. Consequently, the purpose of this study was to assess the fertilizer response of a commercially available, wastewater-recovered struvite material (i.e. Crystal Green) in a plant-less, moist-soil incubation experiment with multiple soil textures (i.e. loam, silt loam, silty clay loam). As hypothesized, re- 
sults demonstrated greater WS- and WAE-P concentrations in the finely ground CG treatment over the first month of incubation than in the pelletized CG treatment in all soils. However, the hypothesis was only partially supported because the finely ground CG treatment did not have a greater WS- and WAE-P response over the course of the entire incubation. Results confirmed the slow-release properties of pelletized CG treatment that have been previously reported, which resulted in a generally similar change in WS- and WAE-P concentration in finely ground and pelletized treatments in each soil after 6 months of incubation. Although a similar $\mathrm{P}$ response occurred between finely ground and pelletized treatments across all soils, WS-P concentration differed among soil textures in both finely ground and pelletized treatments throughout the incubation. Despite the slow-release properties of struvite and the particle size differences of the two forms of CG used in this study, results generated from this study have demonstrated that CG in both finely ground and pelletized forms had a comparable fertilizer-P behavior in multiple soil textures over the course of a 6-month soil incubation experiment.

Results from this study provided valuable insight into the behavior of wastewater-recovered struvite in agronomic soils. Results showed that not only the fertilizer response was affected by the chemical and physical properties of the different soils and fertilizer characteristics themselves, but was also affected by previous management history in similar-textured soils (i.e. SiL 1 ad SiL 2). The choice of which fertilizer-P source to use will clearly need to consider soil texture and field management history to best tailor the most appropriate fertilizer- $\mathrm{P}$ source to the specific setting and management practices where the fertilizer-P will be used for optimal crop production. To accurately assess the applicability of struvite as an alternative fertilizer-P source, additional, in-depth research is still required to better understand struvite behavior compared to other conventional fertilizer-P sources in additional soil textures and soil environments, such as under flooded-soil conditions as is common for rice production.

\section{Acknowledgements}

This work was supported by a research grant from the National Science Foundation (NSF) INFEWS/T3 Program (Award \#1739473).

\section{Conflicts of Interest}

The authors declare no conflicts of interest regarding the publication of this paper.

\section{References}

[1] Steen, I. (1998) Phosphorus Availability in the 21st Century: Management of a Nonrenewable Resource. Phosphorus \& Potassium, 217, 25-31.

[2] Smil, V. (2000) Phosphorus in the Environment: Natural Flows and Human Interferences. Annual Review of Energy and the Environment, 25, 53-88. 
https://doi.org/10.1146/annurev.energy.25.1.53

[3] Le Corre, K.S., Valsami-Jones, E., Hobbs, P. and Parsons, S.A. (2009) Phosphorus Recovery from Wastewater by Struvite Crystallization: A Review. Critical Reviews in Environmental Science and Technology, 39, 433-477.

https://doi.org/10.1080/10643380701640573

[4] Cordell, D., Rosemarin, A., Schröder, J. and Smit, A. (2011) Towards Global Phosphorus Security: A Systems Framework for Phosphorus Recovery and Reuse Options. Chemosphere, 84, 747-758.

https://doi.org/10.1016/j.chemosphere.2011.02.032

[5] Liu, Y., Kumar, S., Kwag, J. and Ra, C. (2012) Magnesium Ammonium Phosphate Formation, Recovery and Its Application as Valuable Resources: A Review. Journal of Chemical Technology \& Biotechnology, 88, 181-189.

https://doi.org/10.1002/jctb.3936

[6] Suh, S. and Yee, S. (2011) Phosphorus Use-Efficiency of Agriculture and Food System in the US. Chemosphere, 84, 806-813.

https://doi.org/10.1016/j.chemosphere.2011.01.051

[7] De-Bashan, L.E. and Bashan, Y. (2004) Recent Advances in Removing Phosphorus from Wastewater and Its Future Use as Fertilizer (1997-2003). Water Research, 38, 4222-4246. https://doi.org/10.1016/j.watres.2004.07.014

[8] Woods, N.C., Sock, S.M. and Daiger, G.T. (1999) Phosphorus Recovery Technology Modeling and Feasibility Evaluation for Municipal Wastewater Treatment Plants. Environmental Technology, 20, 663-679. https://doi.org/10.1080/09593332008616862

[9] Doyle, J.D. and Parsons, S.A. (2002) Struvite Formation, Control and Recovery. Water Research, 36, 3925-3940. https://doi.org/10.1016/S0043-1354(02)00126-4

[10] Rahman, M.M., Salleh, M.A., Rashid, U., Ahsan, A., Hossain, M.M. and Ra, C.S. (2014) Production of Slow Release Crystal Fertilizer from Wastewaters through Struvite Crystallization-A Review. Arabian Journal of Chemistry, 7, 139-155. https://doi.org/10.1016/j.arabjc.2013.10.007

[11] Degryse, F., Baird, R., Da Silva, R.C. and Mclaughlin, M.J. (2016) Dissolution Rate and Agronomic Effectiveness of Struvite Fertilizers-Effect on Soil pH, Granulation and Base Excess. Plant and Soil, 410, 139-152. https://doi.org/10.1007/s11104-016-2990-2

[12] Nascimento, C.A., Pagliari, P.H., Faria, L.D. and Vitti, G.C. (2018) Phosphorus Mobility and Behavior in Soils Treated with Calcium, Ammonium, and Magnesium Phosphates. Soil Science Society of America Journal, 82, 622-631. https://doi.org/10.2136/sssaj2017.06.0211

[13] Pérez, R.C., Steingrobe, B., Romer, W. and Classen, N. (2009) Plant Availability of P Fertilizers Recycled from Sewage Sludge and Meat-and-Bone Meal in Field and Pot Experiments. International Conference on Nutrient Recovery from Wastewater Streams, Vancouver, 10-13 May 2009, 904.

[14] Cabeza, R., Steingrobe, B., Römer, W. and Claassen, N. (2011) Effectiveness of Recycled P Products as P Fertilizers, as Evaluated in Pot Experiments. Nutrient Cycling in Agroecosystems, 91, Article No.: 173. https://doi.org/10.1007/s10705-011-9454-0

[15] Katanda, Y., Zvomuya, F., Flaten, D. and Cicek, N. (2016) Hog-Manure-Recovered Struvite: Effects on Canola and Wheat Biomass Yield and Phosphorus Use Efficiencies. Soil Science Society of America Journal, 80, 135-146. 
https://doi.org/10.2136/sssaj2015.07.0280

[16] Tallboys, P.J., Heppell, J., Roose, T., Healey, J.R., Jones, D.L. and Withers, P.J. (2016) Struvite: A Slow-Release Fertiliser for Sustainable Phosphorus Management? Plant and Soil, 401, 109-123. https://doi.org/10.1007/s11104-015-2747-3

[17] Soil Survey Staff (SSS), Natural Resources Conservation Service (NRCS), United States Department of Agriculture (USDA) (2015) Web Soil Survey. https://websoilsurvey.sc.egov.usda.gov/App/WebSoilSurvey.aspx

[18] Gee, G.W. and Bauder, J.W. (1986) Particle-Size Analysis. In: Klute, A., Ed., Methods of Soil Analysis, Part 1: Physical and Mineralogical Methods, 2nd Edition, Soil Science Society of America, Madison, 383-413. https://doi.org/10.2136/sssabookser5.1.2ed.c15

[19] Zhang, H. and Wang, J.J. (2014) Measurement of Soil Salinity and Sodicity. In: Sikora, F.J. and Moore, K.P., Eds., Soil Test Methods from the Southeastern United States. Southern Cooperative Series Bulletin 419, University of Georgia, 155-157.

[20] Brye, K.R., West, C. and Gbur, E. (2004) Soil Quality Differences under Native Tallgrass Prairie across a Climosequence in Arkansas. The American Midland Naturalist, 152, 214-230. https://doi.org/10.1674/0003-0031(2004)152[0214:SQDUNT]2.0.CO;2

[21] Sikora, F.J. and Kissel, D.E. (2014) Soil pH. In: Sikora, F.J. and Moore, K.P., Eds., Soil Test Methods in Southeastern United States. Southern Cooperative Series Bulletin 419, University of Georgia, Athens, 48-53.

[22] Provin, T. (2014) Total Carbon and Nitrogen and Organic Carbon via Thermal Combustion Analysis. http://aesl.ces.uga.edu/sera6/PUB/MethodsManualFinalSERA6.pdf

[23] Saxton, K., Rawls, W.J., Romberger, J. and Papendick, R. (1986) Estimating Generalized Soil-Water Characteristics from Texture. Soil Science Society of America Journal, 50, 1031-1036. https://doi.org/10.2136/sssaj1986.03615995005000040039x

[24] United States Department of Agriculture (USDA) (2017) Soil-Plant-AtmosphereWater Field, and Pond Hydrology. USDA, Washington, DC. https://hrsl.ba.ars.usda.gov/SPAW/Index.htm

[25] Tucker, M.R. (1992) Determination of Phosphorus by Mehlich-3 Extraction. In: Donohue, S.J., Ed., Soil and Media Diagnostic Procedures for the Southern Region of the United States. Virginia Agriculture Experiment Station Series Bulletin 374, Blacksburg, VA, 6.

[26] Zhang, H., Hardy, D.H., Mylavarapu, R. and Wang, J. (2014) Mehlich-3. In: Sikora, F.J. and Moore, K.P., Eds., Soil Test Methods from the Southeastern United States. Southern Cooperative Series Bulletin 419, University of Georgia, Athens, 101-110.

[27] United States Environmental Protection Agency (USEPA) (1996) Method 3050B: Acid Digestion of Sludges, Sediments, and Soils, Revision 2. Washington DC. https://www.epa.gov/sites/production/files/2015-06/documents/epa-3050b.pdf

[28] Vaneeckhaute, C., Janda, J., Vanrolleghem, P.A., Tack, F.M.G. and Meers, E. (2016) Phosphorus Use Efficiency of Bio-Based Fetilizers: Bioavailability and Fractionation. Pedosphere, 26, 310-325. https://doi.org/10.1016/S1002-0160(15)60045-5

[29] Montalvo, D., Degryse, F. and McLaughlin, M.J. (2014) Fluid Fertilizers Improve Phosphorus Diffusion But Not Lability in Andisols and Oxisols. Soil Science Society of America Journal, 78, 214-224. https://doi.org/10.2136/sssaj2013.02.0075

[30] Everaert, M., Da Silva, R.C., Degryse, F., McLaughlin, M.J. and Smolders, E. (2018) Limited Dissolved Phosphorus Runoff Losses from Layered Doubled Hydroxides 
and Struvite Fertilizers in a Rainfall Simulation Study. Journal of Environmental Quality, 47, 371-377. https://doi.org/10.2134/jeq2017.07.0282

[31] Anderson, R. (2020) Struvite Behavior and Effects as a Fertilizer-Phosphorus Source among Arkansas Soils. M.S. Thesis, University of Arkansas, Fayetteville.

[32] Nongqwenga, N., Muchaonyerwa, P., Hughes, J., Odindo, A. and Bame, I. (2017) Possible Use of Struvite as an Alternative Phosphate Fertilizer. Journal of Soil Science and Plant Nutrition, 17, 581-593. https://doi.org/10.4067/S0718-95162017000300003

[33] Hilt, K., Harrison, J., Bowers, K., Stevens, R., Bary, A. and Harrison, K. (2016) Agronomic Response of Crops Fertilized with Struvite Derived from Dairy Manure. Water Soil Air Pollution, 227, Article No.: 388. https://doi.org/10.1007/s11270-016-3093-7

[34] Robles-Aguilar, A.A., Schrey, S.D., Postma, J.A., Temperton, V.M. and Jablonowski, N.D. (2020) Phosphorus Uptake from Struvite Is Modulated by the Nitrogen form Applied. Journal of Plant Nutrition and Soil Science, 183, 80-90.

[35] Massey, M.S., Davis, J.G., Sheffield, R.E. and Ippolito, J.A. (2007) Struvite Production from Dairy Wastewater and Its Potential as a Fertilizer for Organic Production in Calcareous Soils. CD-Rom Proceedings of the International Symposium on Air Quality and Waste Management for Agriculture, Broomfield, CO, 16-19 September 2007, ASABE Publication Number 701P0907cd.

[36] Diwani, G.E., Rafie, S.E., Ibiari, N.N.E. and. El-Aila, H.I. (2007) Recovery of Ammonia Nitrogen from Industrial Wastewater Treatment as Struvite Slow Releasing Fertilizer. Desalination, 214, 200-214. https://doi.org/10.1016/j.desal.2006.08.019

[37] Kim, D.K., Ryu, H.D., Kim, M.S., Kim, J. and Lee, S.I. (2007) Enhancing Struvite Precipitation Potential for Ammonia Nitrogen Removal in Municipal Landfill Leachate. Journal of Hazardous Materials, 146, 81-85. https://doi.org/10.1016/j.jhazmat.2006.11.054

[38] Antonini, S., Arias, M.A., Eichert, T. and Clemons, J. (2012) Greenhouse Evaluation and Environmental Impact Assessment of Different Urine-Derived Struvite Fertilizers as Phosphorus Sources for Plants. Chemosphere, 89, 1202-1210. https://doi.org/10.1016/j.chemosphere.2012.07.026

[39] Syers, J.K., Johnston, A.E. and Curtin, D. (2008) Efficiency of Soil and Fertilizer Phosphorus Use. FAO Fertilizer and Plant Nutrition Bulletin Number 18.

[40] Cordell, D., Drangert, J.O. and White, S. (2009) The Story of Phosphorus: Global food Security and Food for Thought. Global Environmental Change, 19, 292-305. https://doi.org/10.1016/j.gloenvcha.2008.10.009

[41] Jaffer, Y., Clark, T.A., Pearce, P. and Parsons, S.A. (2002) Potential Phosphorus Recovery by Struvite Formation. Water Research, 36, 1834-1842. https://doi.org/10.1016/S0043-1354(01)00391-8 